\title{
Modelo para avaliação econômica comparativa entre alternativas de sistemas de fixação com elementos roscados
}

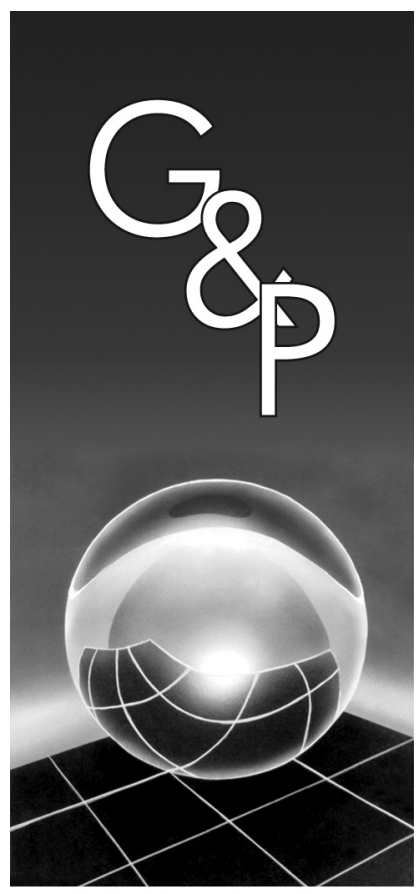

João Carlos Barreto Piekarski

Carlos Cziulik

\section{Resumo}

As demandas junto aos diferentes setores de manufatura têm crescido em termos de qualidade e prazos. Todavia, estas demandas sofrem forte impacto de etapas anteriores, mais notadamente, do estágio de desenvolvimento do produto. Nesta fase, importantes decisões são tomadas, sendo que, em muitos casos, estas são fortemente influenciadas pela experiência ou preferência das pessoas envolvidas na atividade. Outra constatação bastante evidente é a de que, na maioria das vezes, produtos dependem de processos de montagem, que podem assumir diferentes configurações (e.g., uniões fixas ou móveis; reversíveis ou irreversíveis; entre outras). Considerando, principalmente as pressões ambientais, as uniões do tipo "desmontáveis" assumem papel fundamental no desenvolvimento de produtos. Estas podem ser de diferentes tipos, sendo que sua escolha ocorre na etapa de projeto. Assim, o objetivo deste artigo é apresentar o desenvolvimento de um modelo para facilitar a tomada de decisão quanto ao emprego de sistemas de fixação desmontáveis, considerando aspectos econômicos envolvidos nos processos examinados. Os dados de entrada e estruturação do modelo são representativos da realidade industrial, de parâmetros oriundos de literatura e de dados obtidos a partir de experimentos em ambiente controlado. $O$ modelo contempla as considerações de custos nas etapas de: i) aquisição e estocagem; ii) manufatura; iii) montagem; e iv) manutenção; que são etapas principais do ciclo de vida do componente. O conjunto de equações que dá sustentação ao modelo é apresentado em anexo. Um teste preliminar do uso do modelo ilustra que este é capaz de capturar as diferenças de custos entre os sistemas de fixação considerados para determinada montagem, a partir de parâmetros definidos nas etapas iniciais de projeto.

Palavras-chave: Modelo para cálculo de custos. Análise econômica. Sistemas de fixação. Comparativo de custos.

\section{Introdução}

A competitividade está a cada dia mais acirrada entre os diversos fabricantes, fazendo com que as empresas busquem reduzir os custos de seus produtos, visando ampliar ou manter sua participação no mercado. Por outro lado, por exigência dos clientes, a qualidade tem que ser melhorada ou pelo menos mantida, e a busca de soluções alternativas para redução de custos na fase de projeto é constante. Isto faz com que as equipes de projeto, ainda na fase de desenvolvimento, sejam pressionadas a, além de criar soluções inovadoras e funcionais, produzir alternativas compatíveis com o custo-meta que o cliente está disposto a pagar.

A motivação para a criação do modelo apresentado neste artigo é oriunda do crescente interesse das indústrias em reduzir seus custos e porque os projetistas ainda carecem de ferramentas que os auxiliem a decidir qual a melhor opção para um projeto na fase inicial de desenvolvimento dos produtos, sob o ponto de vista econômico. Os métodos existentes e utilizados são focados na manufatura e na montagem. Não foram localizadas abordagens de projeto que considerem o cliente final do produto, que é o responsável pelo sucesso das vendas e pela sobrevivência das indústrias, sob a ótica econômico-financeira.

Desta forma, a necessidade de estimar os custos nas fases iniciais de desenvolvimento de produtos para as soluções concebidas (e.g., fazer a junção de dois componentes, empregando parafusos. Qual é o custo estimado desta solução?) e à dificuldade de se encontrar ferramentas simuladoras que considerem o custo do produto como um todo - da aquisição de matéria-prima até a consideração de manutenção pelo cliente final - caracteriza uma lacuna ainda não endereçada de maneira sistemática pelos meios acadêmicos e na prática. 
O objetivo deste artigo é o de apresentar um modelo para consideração de custos, ainda nos estágios iniciais de desenvolvimento de produto, que visa auxiliar o projetista a definir a melhor alternativa econômico-financeira para a escolha de sistema de fixação de componentes metálicos desmontáveis. Assim, permite ao projetista a comparação das alternativas de sistemas de fixação desmontáveis, visualizando os seus custos relativos ainda no início do projeto.

O modelo aqui apresentado, denominado Pro-Comp, abrange os custos inerentes às diversas fases do ciclo de vida de um produto, iniciando pela aquisição, passando pela manufatura e montagem e, ainda, considerando os custos de manutenção do produto final pelo cliente. Sua estrutura central é baseada em processos industriais e a composição de custos representa a realidade industrial.

\section{Fundamentação teórica}

\subsection{O processo de desenvolvimento de produtos e aspectos do custo final do produto}

Há diversas metodologias de desenvolvimento de produtos disponíveis na literatura que sistematizam o processo de elaboração de uma solução desde a identificação da oportunidade à introdução do produto no mercado (PAHL; BEITZ, 1996; PUGH, 1990; ULLMAN, 1997; ROZENFELD et al., 2006). Apesar da importância da determinação dos custos para o sucesso do produto, o que se nota é que as abordagens consultadas tratam o assunto de forma superficial, principalmente nos estágios iniciais do processo de desenvolvimento. Há várias sugestões de que se deve endereçar os tópicos referentes a custos quando o projeto já estiver em estágios mais avançados ou ainda quando o produto estiver mais formalizado (e.g., no estágio de lote-piloto).

Todavia, a maior parte do custo final de um produto (entre $60 \%$ e $80 \%$ ) é definida durante a fase inicial de projeto do produto (HUNDAL, 1995). Consequentemente, após a definição do projeto, as oportunidades de redução de custo são limitadas. Portanto, é nesta fase que se tem o maior potencial para reduzir os custos (BOOTHROYD et al., 1994).

A General Electric cita que cerca de $75 \%$ dos custos de manufatura são determinados durante o projeto de um produto, sendo que nos casos em que o custo de material representa entre $65 \%$ e $80 \%$ do custo do produto, a fase de projeto pode influenciar $90 \%$ ou mais no custo final de manufatura (DAETZ, 1987).

Para Michaels e Woods (1989), é durante a fase de projeto que se deve maximizar a simplicidade do projeto e dos processos, e minimizar a quantidade e variedade de peças e seu descarte. Cerca de $55 \%$ do material de chapas metálicas são sucatados durante o processo de fabricação, existindo um grande potencial de reduzir custos durante a fase de projeto ao prever a utilização máxima do material de chapas. O projetista deve ter em mente que os custos de inventário (manuseio, estoque e suprimento) fazem parte do custo final do produto.

$\mathrm{Na}$ fase de desenvolvimento do produto, principalmente durante o Projeto Preliminar (PAHL; BEITZ, 1996), define-se a estrutura do produto, os métodos de montagem, as quantidades de peças, os detalhes, os materiais e as tolerâncias das peças, entre outros. Assim, os processos de montagem são estabelecidos basicamente nesta fase por um projetista que, geralmente, não os domina e preocupa-se principalmente em atender às funções do produto e concluir o projeto o mais rápido possível. $\mathrm{O}$ projetista de um produto não deve simplesmente assegurar que este cumpra sua função, mas também deve se preocupar com (ANDREASEN et al., 1988): i) os processos para a produção das peças; ii) os processos para a montagem das peças no produto final.

Para operações que envolvem montagens, os sistemas de fixação desempenham papel fundamental e têm forte influência na estrutura de custos do produto final. Para pequenos volumes de produção de sistemas de fixação desmontáveis, geralmente é mais econômico se empregar porcas e parafusos. Mas, para volumes maiores, a utilização de roscas nas peças principais é mais recomendada (BRALLA et al., 1988).

A função do sistema de fixação inclui uma série de requisitos estruturais e não estruturais (STARK, 1977). Este trabalho está concentrado nos requisitos não estruturais e de cunho econômico.

\subsection{Processos de montagem: considerações}

Para Bralla et al. (1988), o processo de montagem compreende a colocação e a fixação de peças em um conjunto ou produto final. Para os autores, a melhor montagem é a que utiliza menos peças.O tempo para a montagem de produtos depende de vários fatores que afetam o manuseio das peças e ferramentas utilizadas. Entre os fatores que aumentam o tempo de montagem estão: i) necessidade de utilizar duas mãos para a montagem; ii) necessidade de ferramentas; e iii) dificuldade de visão dos componentes sendo montados (BOOTHROYD et al., 1994).

As melhorias mais radicais dos processos de montagem são definidas na fase de projeto do produto, quando se opta por eliminar ou simplificar algumas peças ou montagens, sendo que um produto deve ser projetado para fácil montagem (DFeA - Design for Easy Assembly), devendo seguir algumas recomendações (ANDREASEN et al., 1988): i) projeto simples (i.e., poucas peças, montagem simples e em poucas etapas); ii) projeto limpo (i.e., que proporcione liberdade e visibilidade para a montagem); iii) composição estrutural do produto integrada (i.e., poucas peças e montagens, peças maiores e fáceis de manusear) e diferenciada (i.e., peças 
mais leves e em menor quantidade); e iv) os sistemas de fixação devem evitar montagens (i.e., tendendo a custo zero), evitar peças separadas (principalmente, peças pequenas) e utilizar métodos de produção integrados (i.e., peças fabricadas com formatos que substituam peças adicionais para sua fixação).

A quantidade e a variedade de peças afeta o custo de montagem de um produto, demandando, proporcionalmente, maior quantidade de ferramentas para sua montagem e manutenção (MICHAELS; WOOD, 1989).

\subsection{Composição de custos: contexto}

Para a indústria, o custo de um produto é resultante da transformação de matéria-prima em componentes, ou seja, envolve os custos de aquisição e estocagem de matéria-prima ou subcomponentes (i.e., incluindo o custo de cada peça, a logística de transporte, a área necessária, as embalagens e o manuseio), os custos de manufatura (i.e., máquinas operatrizes, ferramentas, equipamentos, operadores e energia, entre outros) e os custos da montagem nos produtos finais (i.e., operadores, ferramentas e equipamentos, entre outros). A Tabela 1 apresenta uma estrutura típica de composição de custos.

Todavia, o cliente, após adquirir o produto final, também terá custos de manutenção durante a vida útil do bem adquirido. Estes custos envolvem a aquisição de peças, ferramentas, logística, manuseio e estocagem de componentes, tempo gasto para a manutenção, entre outros. Portanto, não se deve analisar o custo de apenas um componente para a decisão sobre sua utilização (ou não), e sim avaliar o custo total do produto e, quando necessário ou possível, verificar seus efeitos junto ao cliente final do produto.

Entretanto, existe escassez de bibliografia relacionada com a estimativa de custos entre processos, considerando as fases iniciais do projeto. As consequências da decisão pela adoção de um ou outro sistema de fixação, nas etapas de montagem e manutenção, geralmente, também não são examinadas.

Desta forma, evidencia-se uma lacuna, que pode ser preenchida pela aplicação de uma sistemática que permita realizar um comparativo de custos entre dois (ou mais) processos e indicar o mais interessante sob o ponto de vista financeiro, ainda nos estágios iniciais do processo de desenvolvimento de produtos.

\section{Proposta de modelo para a avaliação econômica comparativa entre alternativas de sistemas de fixação}

\subsection{Pressupostos para composição do modelo}

Neste trabalho são examinados os sistemas de fixação desmontáveis, constituídos por elementos fixadores e elemento-base feitos em aço, conforme Figura 1, considerando as alternativas que utilizam o processo de furação convencional com brocas helicoidais seguido de rebarbação com brocas para escarear Figura 1a e a furação por escoamento complementada por rosqueamento com machos de conformação Figura $1 b$.

Tabela 1. Composição de custos, conforme Casarotto Filho; Kopittke, (2000).

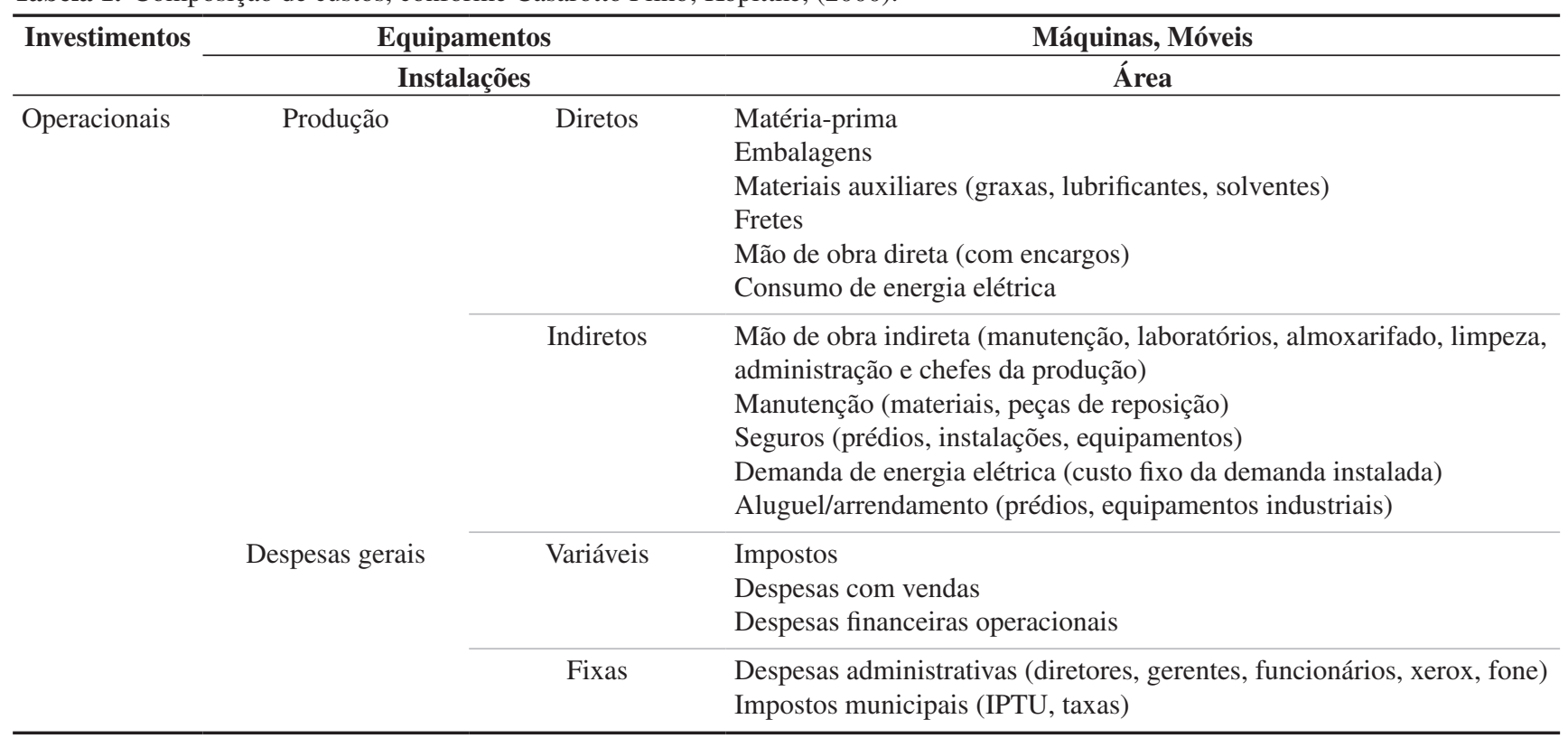



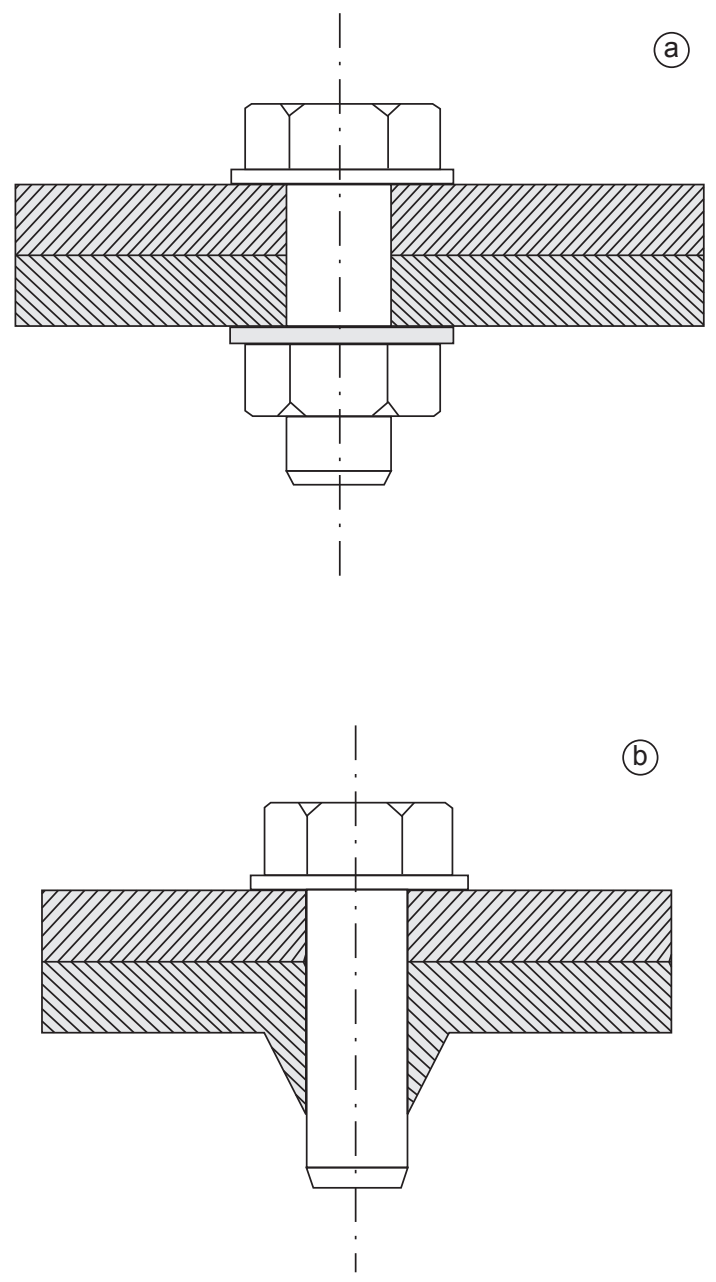

Figura 1. Alternativas de sistemas de fixações desmontáveis.

\subsection{Considerações preliminares}

Existem três grandes áreas que necessitam ser integradas no modelo, visando proporcionar ao projetista a solução mais abrangente e que retrate aspectos econômicos compatíveis: i) Compras e Materiais; ii) Industrial; e iii) Cliente.

O modelo proposto neste trabalho deve servir de ferramenta para o projetista decidir entre alternativas de sistemas de fixação desmontáveis avaliando os custos: i) de aquisição e estocagem dos elementos; ii) de manufatura dos elementos; iii) de montagem; e iv) de manutenção a ser realizada pelo cliente final do produto. Ou seja, analisar os custos de uma forma mais ampla (ver Figura 2).

A definição de estudar três fases industriais do ciclo de vida de um produto (Aquisição e Estocagem, Manufatura e Montagem) surgiu em razão de que estas têm maior influência no custo do produto final (DAETZ, 1987; BOOTHROYD et al., 1994), sendo que a quarta fase (Manutenção), refere-se ao cliente, que nem sempre está satisfeito ou disposto a pagar elevados custos para a manutenção necessária durante a vida do produto adquirido.

\subsection{Descrição do modelo Pro-Comp}

O modelo proposto (de agora em diante, denominado Pro-Comp) permite capturar as consequências das opções iniciais disponíveis ao projetista em cada fase, sob o ponto de vista financeiro, conforme Figura 3.

Conforme Figura 3, o modelo Pro-Comp está dividido em três blocos: i) Especificação do sistema de fixação; ii) Processamento (fases dos processos); iii) Saída com Resultados comparativos.
Decisão do projetista
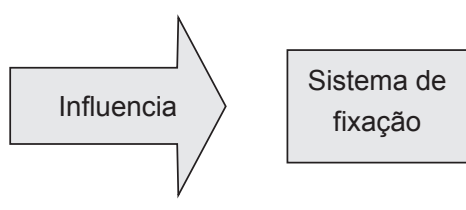

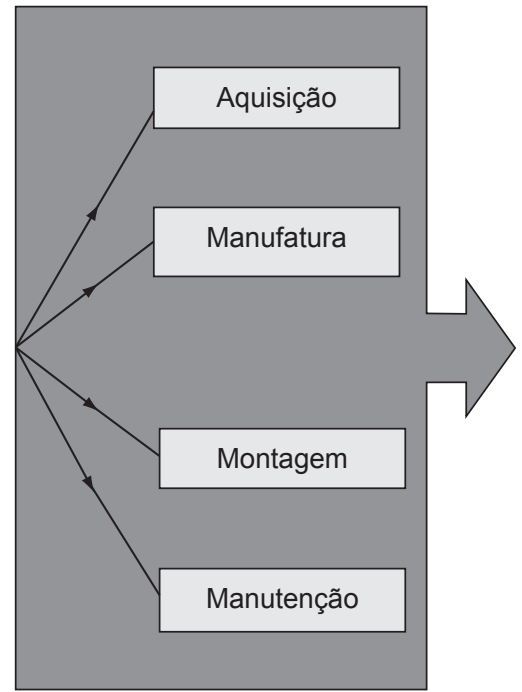

Figura 2. Fases do ciclo de vida do produto consideradas para a definição do modelo. 


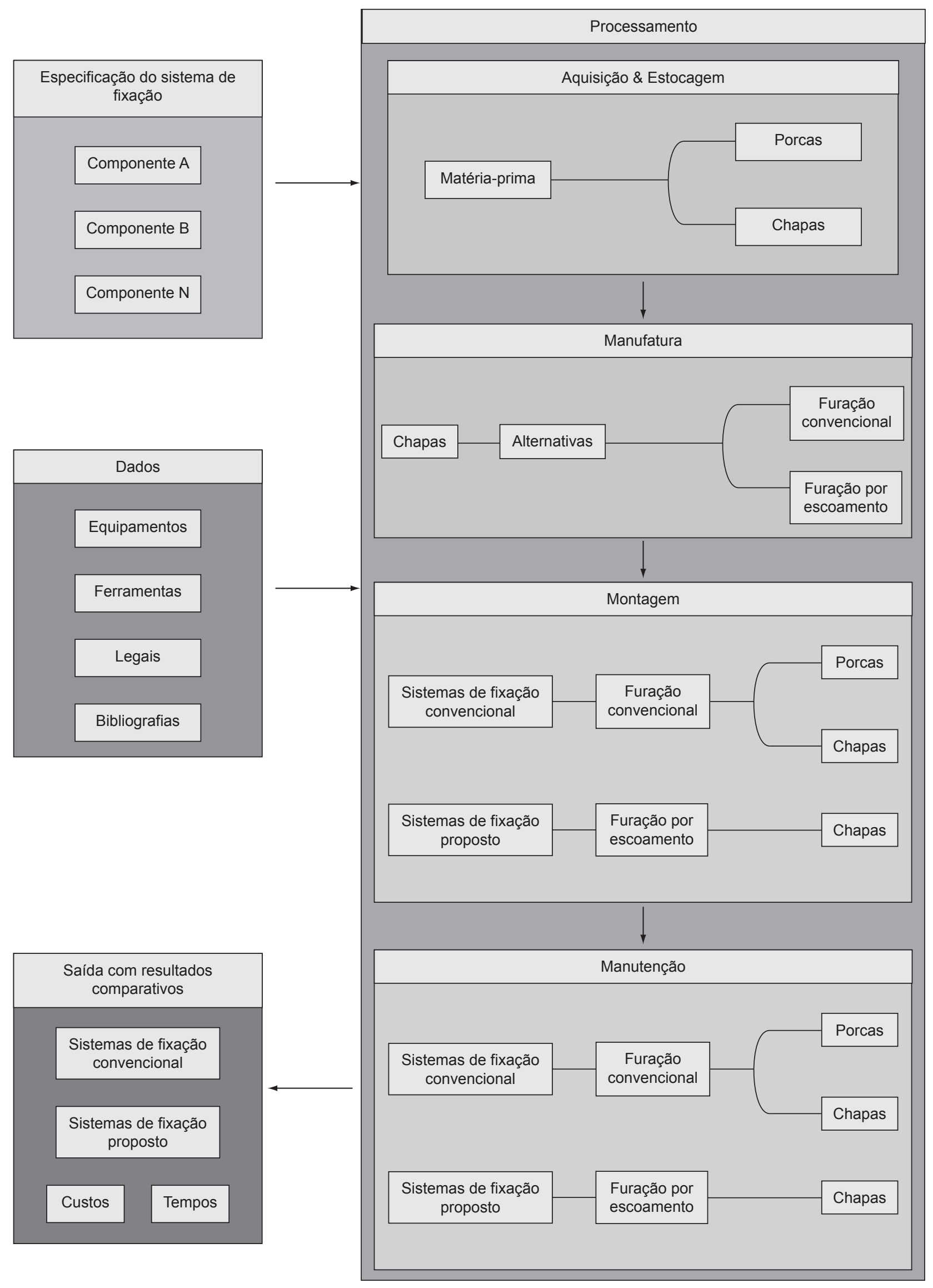

Figura 3. Diagrama ilustrativo do Modelo Pro-Comp. 
O modelo Pro-Comp pode ser entendido como sendo um processador das informações do sistema de fixação (geradas pelo projetista no bloco de especificação do sistema de fixação) que se utiliza de várias informações, dados e equações definidas e disponibilizadas no bloco de processamento (obtidas em literatura, junto aos fabricantes e empresas, e outras definidas durante o decorrer da pesquisa) gerando no bloco de saída os resultados comparativos entre as alternativas escolhidas.

O denominado bloco de processamento é composto por sub-blocos que contêm:

- Dados de equipamentos, ferramentas e outros materiais necessários ao modelo;

- Informações gerais que contêm os custos, tempos, constantes e demais informações diversas não relacionadas diretamente aos equipamentos e ferramentas; e

- Formulários, equações e cálculos utilizados no modelo, para cada fase estudada (Aquisição e Estocagem, Manufatura, Montagem e Manutenção).

\subsection{Considerações e parâmetros do modelo Pro-Comp}

Por se tratar de modelo para comparação financeira entre duas alternativas de processos de manufatura distintos, as considerações e os cálculos serão realizados apenas com os fatores que são influenciados pelas diferenças de processos e que tenham relação expressiva nos resultados.

Os dados, parâmetros e equações utilizados foram obtidos e desenvolvidos com base em informações de algumas empresas contatadas (parâmetros industriais junto à Volvo do Brasil), parâmetros operacionais nas empresas BCC; Guhring; Flowdrill, 1995; Flowdrill, 2000; Flowdrill, 2001; Drabus, 2001; Unimex, 2001; SKF, 1987; e em diversas literaturas (OSG, 2001; VALE, 1975; FERRARESI, 1970; HICKS et al., 1985; BOOTHROYD et al., 1994; DELOITTE TOUCHE TOHMATSU, 2002; VIANNA, 2000; BARNES, 1995; TOLEDO Jr., 1986; RECEITA FEDERAL, 2003).

Os valores de referência são fundamentados a partir de situação real e, para efeitos comparativos, estão apresentados na forma de UM (Unidade Monetária). Isto visa preservar as fontes de informação, sem prejudicar a análise dos resultados.

O valor da UM (Unidade Monetária) foi definido como sendo o valor em reais $(\mathrm{R} \$$ ) multiplicado por um fator. O modelo foi idealizado para aplicações feitas com Chapas Finas de Aço ABNT 1020, espessura de até 6 mm. As unidades de medida são as permitidas no Sistema Internacional.
A seção 6 contém um sumário das equações desenvolvidas e empregadas no modelo.

\subsection{Especificação do sistema de fixação}

$\mathrm{Na}$ área de projeto, durante a etapa conceitual, definem-se os requisitos técnicos dos elementos que compõem o produto (e.g., quantidades, dimensões, materiais, entre outros).

A Tabela 2 traz um modelo de ficha, desenvolvida neste trabalho, para o registro da especificação do sistema de fixação.

\subsection{Aquisição e Estocagem}

$\mathrm{Na}$ área de compras e materiais, consideram-se os custos de aquisição e estocagem dos elementos que compõem o sistema de fixação. Entre os fatores que influenciam os resultados desta fase, tem-se o custo da matéria-prima, custo da mão de obra e de equipamentos para recebimento, controle de qualidade e de estoque, movimentação, expedição, custos de embalagens, custo da área necessária para o estoque e custos administrativos em geral.

O manuseio do estoque e o seu transporte (incluindo os equipamentos necessários) até a área de manufatura também devem ser considerados. Entretanto, por ser um custo de difícil definição em função das inúmeras variáveis existentes (localização, layout, dimensões e pesos das peças, entre outros), este modelo não considera os custos decorrentes das peças adicionais (porcas) utilizadas na alternativa de furação convencional. Porém, sabe-se que este fator aumenta o custo do produto final que utiliza o processo de furação convencional. Assim, neste modelo estão considerados os fatores geradores de custos, conforme Tabela 3.

\subsection{Manufatura}

$\mathrm{Na}$ área industrial considera-se primeiramente a manufatura ou fabricação dos elementos, na qual se encontram os custos dos equipamentos, das ferramentas, dos dispositivos, das áreas ocupadas para equipamentos e estoques intermediários, mão de obra direta, materiais auxiliares, embalagens, sucateamento de matéria-prima e custos administrativos, entre outros. Um detalhamento dos principais elementos está descrito na Tabela 4.

\subsection{Montagem}

A montagem é a segunda atividade que compõe a área industrial. As influências dos diversos parâmetros nos custos de montagem estão relacionadas a fatores como: mão de obra, ferramentas necessárias para a montagem, área de trabalho e de estocagem, embalagens, bancadas e energia para acionamento das ferramentas. A Tabela 5 contém os principais fatores geradores de custos referentes à montagem. 


\subsection{Manutenção anual}

Conforme descrito, este trabalho considera apenas os sistemas desmontáveis, portanto sujeitos à manutenção.

Durante a vida do produto, o cliente poderá ter necessidade de realizar Manutenção no produto. Assim, existem diversos fatores que influenciam positiva ou negativamente nos custos de manutenção, bem como na percepção do cliente sobre o produto. Entre estes, estão os custos da mão de obra e de ferramentas, quantidade de manutenções no período, dificuldade de acesso e custo de peças, entre outros.

O modelo Pro-Comp não tem como objetivo avaliar os fatores técnicos e sim os processos de desmontagem e montagem, que ocorrem quando da realização da manutenção. Os custos avaliados incluem os custos fixos das ferramentas (chaves combinadas) utilizadas nas duas alternativas e os tempos necessários para as movimentações dos parafusos, porcas e ferramentas, com ênfase nos fatores que são diferentes entre as alternativas estudadas.

A quantidade de manutenções requeridas é também uma definição de projeto (não cabendo neste trabalho sua definição) e é dependente de uma série de fatores de projeto e de utilização do produto final. A Tabela 6 apresenta os principais fatores referentes à manutenção.

\subsection{Desenvolvimento das equações}

Para este trabalho adotou-se uma abordagem de desenvolvimento das equações conforme encontrado em Piekarski, (2004).

Para ilustrar o roteiro percorrido visando o desenvolvimento do conjunto de equações (Tabelas 12, 13, 14 e 15), apresenta-se aqui, como exemplo, a obtenção da equação Custo Fixo de Equipamentos:

Estes custos representam os valores que devem ser pagos independentemente da produção de peças e são divididos pelo volume de produção anual dos sistemas de fixação (Equação 1).

$$
\begin{gathered}
C F_{\text {EQUIP }}=C_{\text {EspaçoEQUIP }}+C_{\text {DEPREQUIP }}+ \\
+C_{\text {SEGEQUIP }}+C_{\text {FINANCEQUIP }}
\end{gathered}
$$

em que:

- $C F_{\text {EQUIP }}=$ custo fixo do equipamento (UM/ano);

- $C_{\text {EspacoEQUIP }}=$ custo do espaço utilizado pelo equipamento (UM/ano);

- $C_{\text {DEPREQUIP }}=$ custo de depreciação do equipamento (UM/ano);

- $C_{\text {SEGEQUIP }}=$ custo de seguro do equipamento (UM/ ano);

- $C_{\text {FINANCEQUIP }}=$ custo de oportunidade sobre o capital investido nos equipamentos (UM/ano).

Sendo (Equação 2),

$$
C_{\text {Espa६oEQUIP }}=A .668,71
$$

em que:

- $A$ = área ocupada pelo equipamento $\left(\mathrm{m}^{2}\right)$;

- 668,71 = custo em UM de cada unidade de área (UM/ $\left.\mathrm{m}^{2}\right)$.

Tabela 2. Modelo da ficha de especificação do sistema de fixação.

\begin{tabular}{lc}
\hline \multicolumn{2}{c}{ Especificação do sistema de fixação } \\
\hline Descrição da peça & Chapa \\
Material da chapa & Aço 1020 \\
Espessura da chapa & $4,25 \mathrm{~mm}$ \\
Comprimento da chapa & $200 \mathrm{~mm}$ \\
Largura da chapa & $100 \mathrm{~mm}$ \\
Dimensões da rosca & M14 \\
Quantidade de parafusos por conjunto & 10 \\
Quantidade de conjuntos por período & 1000 por ano \\
Necessidade de manutenções pelo cliente & 2 por ano \\
\hline
\end{tabular}

Tabela 3. Fatores considerados no âmbito de custos de aquisição e estocagem.

\begin{tabular}{ll}
\hline \multicolumn{1}{c}{ Fator } & \multicolumn{1}{c}{ Descrição } \\
\hline Matéria-prima & Este é o fator de maior influência no custo final de um produto conforme apresentado na literatura. Como \\
& matéria-prima, considera-se todo o material adquirido seja ele já acabado (pronto para uso) ou a ser \\
& processado. No modelo Pro-Comp estão incluídos os custos de aquisição dos elementos do sistema de \\
& fixação que são diferentes entre as alternativas comparadas: i/ elemento fixador com rosca interna (porca); \\
& e ii/ elemento base (chapa). Os valores incluem: fretes, inspeções e controles, necessários para cada \\
& peça. O custo de aquisição da chapa pré-cortada (a ser furada) nas dimensões definidas por projeto está \\
& considerado nas duas opções, pois será utilizado nas demais fases da comparação. O preço por peso de \\
& chapa varia de acordo com a espessura e processo de laminação. \\
& O modelo considera os preços obtidos junto aos fornecedores.
\end{tabular}

Área de estocagem de São considerados o valor da área, das construções, seguros, manutenção, depreciação e custos financeiros. matéria-prima

Embalagens para estocagem de matéria-prima
Engloba o custo de aquisição, depreciação, vida útil e custos financeiros.

Somente será considerado o custo de embalagens adicionais necessárias para o armazenamento com os elementos que diferem entre as alternativas estudadas. 
Tabela 4. Fatores considerados no âmbito de custos na área industrial, considerando aspectos de fabricação.

\begin{tabular}{|c|c|}
\hline Fator & Descrição \\
\hline Equipamentos & $\begin{array}{l}\text { Este fator é bastante representativo no cálculo de custos, pois os equipamentos possuem elevados custos de } \\
\text { aquisição que resultam em grande parcela componente do custo final do produto. O cálculo de custo dos } \\
\text { equipamentos pode ser dividido entre custos fixos e variáveis. Os primeiros são relacionados à sua aquisição (i.e., } \\
\text { custo, depreciação, vida útil, juros, área utilizada, seguros) e independem da operação, } \\
\text { manufatura ou produção de componentes. Já os custos variáveis estão relacionados diretamente } \\
\text { ao volume de componentes produzidos (i.e., manutenção, consumo de energia). }\end{array}$ \\
\hline
\end{tabular}

Mão de obra direta $\mathrm{O}$ custo da mão de obra direta utilizada na manufatura considera o tempo total para a instalação e retirada de ferramentas, a preparação (set-up) inicial dos equipamentos e a operação (tempos de aproximação, trabalho efetivo e retorno). O modelo Pro-Comp considera também os custos de mão de obra adicional necessária para a limpeza de equipamentos em função dos diferentes processos de manufatura.

Ferramentas para Ferramentas para manufatura são consideradas como consumíveis, ou seja, são utilizadas por determinado manufatura período (vida útil) e descartadas, sendo que, em alguns casos, podem ser recuperadas (e.g., afiação, enchimento). Assim, o cálculo de custos das ferramentas inclui o custo de aquisição, vida da ferramenta e capacidades. Não foi considerada a possibilidade de afiação de ferramentas (brocas convencionais), pois no modelo as brocas escolhidas são feitas em aço-rápido possuindo um baixo custo de aquisição em relação à afiação. As principais ferramentas são: i/ ferramenta para furação por escoamento; ii/ machos para conformação; iii/ brocas helicoidais; iv/ brocas escareadoras (ou para rebarbação).

Tratamento de A produção de sucata resultante de processos de corte, normalmente na forma de cavacos, é indesejável, mas Sucata é um fato real, e assim precisa ser tratada. O modelo considera a quantidade de material resultante de cada processo, computando o volume retirado de cada furo no caso da furação convencional (com brocas) e transforma em peso, sendo que o material removido só pode ser aproveitado como sucata (neste caso, somente a furação convencional gera cavacos. Os custos das embalagens e áreas adicionais necessárias para o armazenamento da sucata produzida na furação convencional também são considerados).

Materiais auxiliares Neste âmbito, são incluídos outros materiais utilizados nos processos de manufatura, como: pastas, óleos de corte, fluidos, panos, estopas, luvas, máscaras, entre outros.

Tabela 5. Fatores considerados no âmbito de custos na área industrial, considerando aspectos de montagem.

\begin{tabular}{ll}
\hline \multicolumn{1}{c}{ Fator } & \multicolumn{1}{c}{ Descrição } \\
\hline Mão de obra direta (montagem) & $\begin{array}{l}\text { Considera os tempos de montagem dos elementos no } \\
\text { conjunto ou produto final e o valor da mão de obra pelo período de tempo. }\end{array}$ \\
\cline { 2 - 3 } Ferramentas para montagem & $\begin{array}{l}\text { A utilização de ferramentas no processo de montagem varia de acordo com o que se deseja } \\
\text { montar, podendo necessitar de ferramentas complexas ou simples, ferramentas automáticas ou } \\
\text { não, ferramentas de acionamento mecânico, elétrico ou pneumático, ou ainda manuais. Tem- } \\
\text { se ainda que nem todos os processos de montagem necessitam de ferramentas (e.g., porcas } \\
\text { tipo borboleta). No caso estudado, as ferramentas geralmente são as chaves combinadas e as } \\
\text { chaves pneumáticas. Os fatores que compõem os custos são: custos de aquisição, vida útil, } \\
\text { depreciação, manutenção e capacidade das diferentes ferramentas. }\end{array}$
\end{tabular}

Área de estocagem intermediária

Considera a área adicional necessária para a estocagem das porcas necessárias na alternativa de furação convencional.

Embalagens para estocagem $\quad$ Envolve a embalagens adicionais necessárias para a estocagem intermediária das porcas utilizadas na alternativa de furação convencional.

Tabela 6. Fatores considerados no âmbito de custos de manutenção.

\begin{tabular}{ll}
\hline \multicolumn{1}{c}{ Fator } & \multicolumn{1}{c}{ Descrição } \\
\hline $\begin{array}{l}\text { Mão de obra para manutenção } \\
\text { pelo cliente }\end{array}$ & $\begin{array}{l}\text { Considera os tempos de desmontagem e montagem dos elementos no } \\
\text { produto final e o valor da mão de obra pelo período de tempo. }\end{array}$ \\
\cline { 2 - 2 } $\begin{array}{l}\text { Ferramentas para manutenção } \\
\text { pelo cliente }\end{array}$ & $\begin{array}{l}\text { A utilização de ferramentas na manutenção varia de acordo com o que se necessita desmontar } \\
\text { e montar, e é resultante do projeto conceitual, podendo ser de diversas formas, acionamentos, } \\
\text { complexidade e tamanhos e, em alguns casos, não há necessidade de utilizar ferramentas. No } \\
\text { caso dos sistemas de fixação, as ferramentas utilizadas pelos clientes são geralmente as chaves } \\
\text { combinadas e as chaves pneumáticas. No modelo Pro-Comp, consideram-se as ferramentas } \\
\text { utilizadas na desmontagem e montagem do sistema de fixação. Assim, para o caso em que se } \\
\text { utilizam porcas (utilizadas na furação convencional) estão consideradas duas chaves combinadas e } \\
\text { para a alternativa que utiliza o processo de furação por } \\
\text { escoamento com rosca conformada, apenas uma ferramenta. }\end{array}$ \\
\end{tabular}


As ferramentas para fabricação e as manuais não possuem este componente devido ao seu tamanho e instalação.

e (Equação 3),

$$
C_{\text {DEPREQUIP }}=C_{E Q U I P} / V U
$$

em que:

- $C_{E Q U I P}=$ Custo de aquisição do Equipamento (UM);

- $V U$ = Vida Útil (anos), sendo que as ferramentas para manufatura possuem sua vida determinada pelas condições de operação e não pela legislação.

e (Equação 4),

$$
C_{S E G E Q U I P}=C_{E Q U I P} . S E Q
$$

em que:

- $S E Q=$ custo de seguro do equipamento foi definido como sendo $1 \%$ ao ano sobre o valor do equipamento, conforme informações da empresa citada em 3.4., sendo que as ferramentas para manufatura, ferramentas manuais e embalagens não possuem seguro.

e (Equação 5),

em que:

$$
C_{\text {FINANCEQUIP }}=C_{E Q U I P} \cdot j
$$

- $j=$ taxa de interesse considerada pela empresa citada em 3.4. (no caso $15 \%$ ao ano).

Utilizando as equações e os valores definidos, tem-se que o custo fixo do equipamento ao ano é representado por (Equação 6):

$$
\begin{gathered}
C_{F E Q U I P}=A \cdot 668,71+ \\
+C_{E Q U I P} \cdot(1 / V U+S E Q+0,15)
\end{gathered}
$$

Dividindo-se o valor da equação Eq. 6 pela quantidade de conjuntos de sistema de fixação produzidos no ano, tem-se (Equação 7):

em que:

$$
\begin{gathered}
K_{F E Q U I P}=[A .668,71+ \\
\left.+C_{E Q U I P} \cdot(1 / V U+S E Q+0,15)\right] / Q S F
\end{gathered}
$$

- $K_{\text {FEQUIP }}=$ custo fixo do equipamento para cada sistema de fixação (UM);

- $Q S F=$ quantidade de sistemas de fixação a serem produzidos por ano.

Utilizando-se como base a equação acima, tem-se o custo fixo do equipamento para cada sistema de fixação (Equação 8):

$$
K_{F E Q U I P}=\left(A \cdot 668,71+C_{E Q U I P} \cdot 0,26\right) / Q S F
$$

\subsection{Informações gerais}

Com o intuito de facilitar a alteração de valores utilizados em vários cálculos, foi criado um banco de dados com informações utilizadas em várias fases e equações necessárias para os cálculos. Esta decisão também proporciona a liberdade de aplicar o modelo Pro-Comp às situações individuais de cada projetista, desde que respeitadas suas premissas básicas. A ficha apresentada na Tabela 7 foi desenvolvida neste estudo para o registro de dados econômicos, técnicos e administrativos, que serão utilizados para configuração inicial do modelo.

\subsection{Saída dos resultados comparativos}

Os resultados do cômputo dos cálculos, considerando as alternativas comparadas, são apresentados na forma de uma Tabela com os custos de Aquisição e Estocagem, Manufatura, Montagem e Custo Final por Sistema de Fixação, e Custo Anual de Manutenção e os tempos de Manufatura, Montagem e Tempo Final por Sistema de Fixação, e Tempo Anual para Manutenção.

Os resultados dos custos apresentados na Tabela 8 estão expressos em Unidade Monetária (UM) e os tempos em segundos (s). Como estes valores representam as diferenças obtidas entre as duas alternativas avaliadas e não os custos reais finais de cada sistema de fixação, optou-se por apresentá-los no modo Saída de Resultados, em relação à alternativa que utiliza a Furação Convencional. Assim, os valores de cada linha da Tabela de resultados são divididos pelo valor total de custo ou de tempo resultante nos cálculos da alternativa de furação convencional, cujo custo total será sempre considerado como sendo uma Unidade de Comparação Monetária (UCM) e o tempo total de fabricação como sendo uma Unidade de Comparação de Tempo (UCT). A Tabela 9 apresenta o formato desenvolvido neste trabalho já com os resultados calculados, conforme descrito.

Os resultados superiores à unidade (UCM ou UCT) indicam que a alternativa Furação por Escoamento seguido de Rosqueamento por Conformação é pior (mais caro e/ou mais demorado) e os resultados inferiores à unidade indicam que esta alternativa é mais interessante sob o ponto de vista financeiro e/ou tempos.

Com o objetivo de agilizar o processo de execução dos cálculos, o modelo foi implementado em planilha MS Excel, conforme Figura 4.

\section{Teste preliminar do modelo}

Para a verificação do modelo proposto, são conduzidos cálculos manuais com cada equação conceitual (ver resultados na Tabela 10) e depois se utilizam as equações sumarizadas na seção 6, obtendo os valores apresentados na Tabela 11 .

Neste caso, o estudo envolve uma demanda de um cliente que necessita adquirir anualmente 5000 produtos conforme Figura 5, compostos pelos elementos A, B, C, D e E:

- Dois elementos base em chapa plana de aço ABNT 1020, com as dimensões $25 \mathrm{~mm}$ de largura por $250 \mathrm{~mm}$ de comprimento e espessura de $3 \mathrm{~mm}$ (C); 
- Dois elementos auxiliares feitos em chapa de $5 \mathrm{~mm}$ com dimensões $250 \mathrm{~mm}$, largura $25 \mathrm{~mm}$ e altura de $100 \mathrm{~mm}$, dobrada conforme desenho, também em aço (B);

- Quatro conjuntos de elementos fixadores com rosca M8 (D e E); e

- Uma base em madeira de $250 \mathrm{~mm}$ por $450 \mathrm{~mm}$, com espessura de $20 \mathrm{~mm}$ (A).

Aplicando-se no elemento $C$ as equações apresentadas na seção 6, obtêm-se os valores apresentados na Tabela 10 .

Verifica-se que, para este caso, a alternativa que utiliza a furação por escoamento seguida por rosqueamento por conformação apresenta valores de custos menores que

Tabela 7. Modelo da ficha preenchida com informações econômicas e administrativas.

\begin{tabular}{lcc}
\hline \multicolumn{3}{c}{ Informações gerais } \\
\hline Nível econômico & Mês/ano & Setembro/2003 \\
Energia elétrica & 0,5245 & $\mathrm{UM} / \mathrm{kWh}$ \\
Mão-de-obra & Salários com encargos \\
Operador de máquinas & 36,63 & $\mathrm{UM} / \mathrm{h}$ \\
Montador & 36,89 & $\mathrm{UM} / \mathrm{h}$ \\
Mecânico de manutenção & 59,77 & $\mathrm{UM} / \mathrm{h}$ \\
Turno de operação & $8 \mathrm{~h} / \mathrm{dia}$ & $220 \mathrm{dias} / \mathrm{ano}$ \\
Custo da área predial & $2.622,38$ & $\mathrm{UM} / \mathrm{m}^{2}$ \\
Seguro predial & $5 \%$ & ao ano \\
Seguro de equipamentos & $1 \%$ & ao ano \\
Manutenção predial & $1,5 \%$ & ao ano \\
Manutenção de equipamentos & $2 \%$ & ao ano \\
Juros de oportunidade & $15 \%$ & ao ano \\
\hline
\end{tabular}

Tabela 8. Modelo da ficha com os resultados absolutos dos cálculos.

\begin{tabular}{lcc}
\hline \multicolumn{1}{c}{$\begin{array}{c}\text { Custos } \\
\text { (unidade monetária) }\end{array}$} & $\begin{array}{c}\text { Furação } \\
\text { convencional }\end{array}$ & $\begin{array}{c}\text { Furação por } \\
\text { escoamento }\end{array}$ \\
\hline Aquisição e estocagem & 0,46 & 0,18 \\
Manufatura & 0,53 & 0,76 \\
Montagem & 0,12 & 0,00 \\
Custo final do & 1,10 & 0,94 \\
sistema de fixação & & \\
Custo de manutenção pelo & 11,24 & 5,62 \\
cliente por ano & & \\
Tempos (s) & & \\
Manufatura & 32,89 & 25,92 \\
Montagem & 11,01 & 0,39 \\
Tempo final do & 43,90 & 26,31 \\
sistema de fixação & & \\
Tempo para manutenção & 29,02 & 14,51 \\
por ano & & \\
\hline
\end{tabular}

a furação convencional em todas as fases do processo (Aquisição e Estocagem, Manufatura, Montagem e Manutenção) (Tabela 10).

Aplicando-se nos resultados apresentados nas Tabela 10 o exposto na seção 3.12, obtêm-se os custos comparativos entre as alternativas, como apresentado na Tabela 11.

Analisando-se os resultados obtidos, observa-se que o custo da alternativa de furação por escoamento seguida por rosqueamento por conformação é equivalente à metade do custo resultante do processo de furação convencional (com brocas) e consome $57 \%$ menos tempo para que todas as atividades sejam executadas.

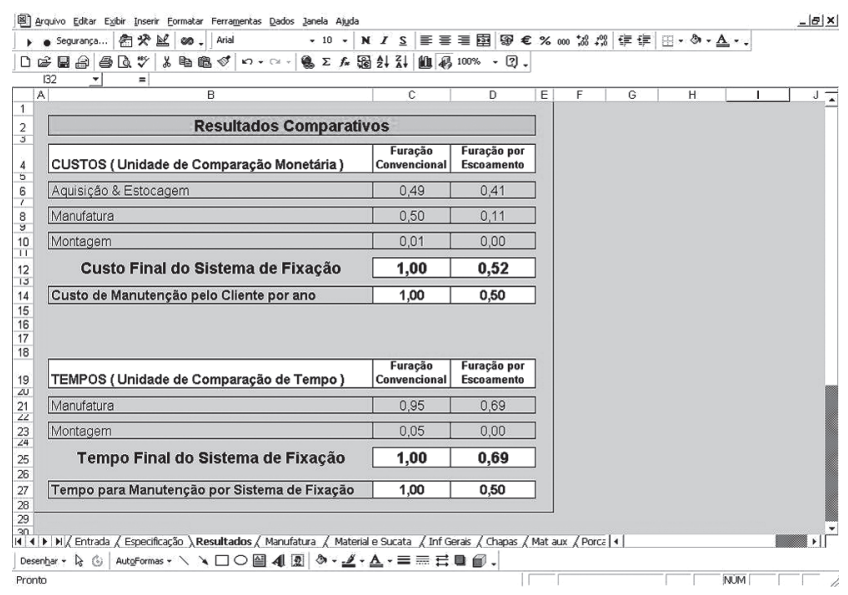

Figura 4. Modelo de Saída com resultados comparativos feito no Excel.

Tabela 9. Modelo da ficha de saída com os resultados comparativos.

\begin{tabular}{lcc}
\hline \multicolumn{3}{c}{ Resultados comparativos } \\
\hline $\begin{array}{c}\text { Custos (unidade de } \\
\text { comparação monetária) }\end{array}$ & $\begin{array}{c}\text { Furação } \\
\text { convencional }\end{array}$ & $\begin{array}{c}\text { Furação por } \\
\text { escoamento }\end{array}$ \\
\hline $\begin{array}{l}\text { Aquisição e estocagem } \\
\text { Manufatura }\end{array}$ & 0,42 & 0,16 \\
Montagem & 0,48 & 0,69 \\
$\begin{array}{l}\text { Custo final do sistema de } \\
\text { fixação }\end{array}$ & 0,11 & 0,00 \\
$\begin{array}{l}\text { Custo de manutenção pelo } \\
\text { cliente por ano }\end{array}$ & 1,00 & 0,86 \\
\hline $\begin{array}{l}\text { Tempos } \\
\text { (unidade de comparação de tempo) }\end{array}$ & 0,50 \\
$\begin{array}{l}\text { Manufatura } \\
\text { Montagem }\end{array}$ & 0,75 & \\
$\begin{array}{l}\text { Tempo final do } \\
\text { sistema de fixação }\end{array}$ & 0,25 & 0,59 \\
$\begin{array}{l}\text { Tempo para manutenção } \\
\text { por sistema de fixação }\end{array}$ & 1,00 & 0,01 \\
\hline
\end{tabular}


Tabela10a. Resultadoscomosvaloresabsolutosdoscálculosdecustos e tempos. Excerto da Tabela com os resultados dos cálculos de custos (modo manual).

\begin{tabular}{|c|c|c|c|}
\hline & & $\begin{array}{c}\text { Furação } \\
\text { convencional }\end{array}$ & $\begin{array}{l}\text { Furação por } \\
\text { escoamento }\end{array}$ \\
\hline \multirow{4}{*}{$\begin{array}{l}\text { Aquisição e } \\
\text { estocagem }\end{array}$} & KAE & 1,5169 & 0,6578 \\
\hline & KMP & 1,4978 & 0,6578 \\
\hline & $\begin{array}{l}\text { KEspaçoEMB } \\
\text { Porcas }\end{array}$ & 0,0185 & \\
\hline & KFEMBPorcas & 0,0006 & \\
\hline \multirow[t]{13}{*}{ Manufatura } & KMA & 5,3230 & 2,4002 \\
\hline & KFEQUIP & 1,0763 & 1,6553 \\
\hline & KVEQUIP & 0,0038 & 0,0093 \\
\hline & KMOD & 0,8038 & 0,4094 \\
\hline & KFL & & 0,1797 \\
\hline & $\mathrm{KMC}$ & & 0,0390 \\
\hline & KBRO & 0,0257 & \\
\hline & KESC & 0,0132 & \\
\hline & KEspaçoEMBSucata & 0,0185 & \\
\hline & KFEMBSucata & 0,0006 & \\
\hline & KAUXFL & & 0,1042 \\
\hline & KAUXMC & & 0,0032 \\
\hline & KAUXBRO & 3,3811 & \\
\hline \multirow[t]{5}{*}{ Montagem } & KM & 0,1326 & 0,0040 \\
\hline & KMOM & 0,1128 & 0,0040 \\
\hline & KFFMON & 0,0007 & \\
\hline & KEspaçoEMBPorcas & 0,0185 & \\
\hline & KFEMPorcas & 0,0006 & \\
\hline \multirow{3}{*}{$\begin{array}{l}\text { Manutenção } \\
\text { anual }\end{array}$} & KMC & 13,6644 & 6,7931 \\
\hline & KMOC & 0,5464 & 0,2341 \\
\hline & KFFCL & 13,1180 & 6,5590 \\
\hline
\end{tabular}

Tabela 11a. Resultados comparativos dos cálculos de custos e tempos. Cálculos de custos (manuais).

\begin{tabular}{lcc}
\hline \multicolumn{1}{c}{ Item } & $\begin{array}{c}\text { Furação } \\
\text { convencional } \\
\text { (UCM) }\end{array}$ & $\begin{array}{c}\text { Furação por } \\
\text { escoamento } \\
\text { (UCM) }\end{array}$ \\
\hline $\begin{array}{l}\text { Aquisição e } \\
\text { estocagem (KAE) }\end{array}$ & 0,22 & 0,09 \\
Manufatura (KMA) & 0,76 & 0,34 \\
$\begin{array}{l}\text { Montagem (KM) } \\
\text { Total do }\end{array}$ & 0,02 & 0,00 \\
Sistema de Fixação & 1,00 & 0,44 \\
\hline & $(\mathrm{UCM} / \mathrm{ano})$ & $(\mathrm{UCM} / \mathrm{ano})$ \\
$\begin{array}{l}\text { Manutenção Anual } \\
\text { (KMC) }\end{array}$ & 1,00 & 0,50 \\
\hline
\end{tabular}

Tabela 10b. Resultados com os valores absolutos dos cálculos de custos e tempos. Excerto da Tabela contendo os resultados dos cálculos de tempos (modo manual).

\begin{tabular}{|c|c|c|c|}
\hline & & $\begin{array}{c}\text { Furação } \\
\text { convencional }\end{array}$ & $\begin{array}{c}\text { Furação } \\
\text { escoameto }\end{array}$ \\
\hline \multirow[t]{28}{*}{ Manufatura } & $\mathrm{tiFL}$ & & 0,0009 \\
\hline & tiMC & & 0,0011 \\
\hline & tiBRO & 0,0108 & \\
\hline & tiESC & 0,0006 & \\
\hline & tpeFL & & 0,3600 \\
\hline & tpeMC & & 0,4320 \\
\hline & tpeBRO & 4,3200 & \\
\hline & tpeESC & 0,2400 & \\
\hline & tcpFL & & 1,4000 \\
\hline & tcpMC & & 1,4000 \\
\hline & tcpBRO & 1,4000 & \\
\hline & tcpESC & 1,4000 & \\
\hline & tapFL & & 4,8667 \\
\hline & tapMC & & 0,0000 \\
\hline & tapBRO & 3,1745 & \\
\hline & tapESC & 3,3333 & \\
\hline & texFL & & 8,0000 \\
\hline & texMC & & 10,5126 \\
\hline & texBRO & 3,8094 & \\
\hline & texESC & 4,0000 & \\
\hline & tafFL & & 4,8667 \\
\hline & tafMC & & 0,0000 \\
\hline & tafBRO & 3,1745 & \\
\hline & tafESC & 3,3333 & \\
\hline & tmpFL & & 2,8000 \\
\hline & tmpMC & & 2,8000 \\
\hline & tmpBRO & 2,8000 & \\
\hline & tmpESC & 5,6000 & \\
\hline
\end{tabular}

Tabela 11b. Resultados comparativos dos cálculos de custos e tempos. Cálculos de tempos (manuais).

\begin{tabular}{lcc}
\hline Item & $\begin{array}{c}\text { Furação } \\
\text { convencional } \\
\text { (UCT) }\end{array}$ & $\begin{array}{c}\text { Furação por } \\
\text { escoamento } \\
\text { (UCT) }\end{array}$ \\
\hline Manufatura & 0,88 & 0,45 \\
Montagem & 0,12 & 0,00 \\
Total do sistema de fixação & 1,00 & 0,45 \\
Manutenção & 1,00 & 0,43 \\
\hline
\end{tabular}



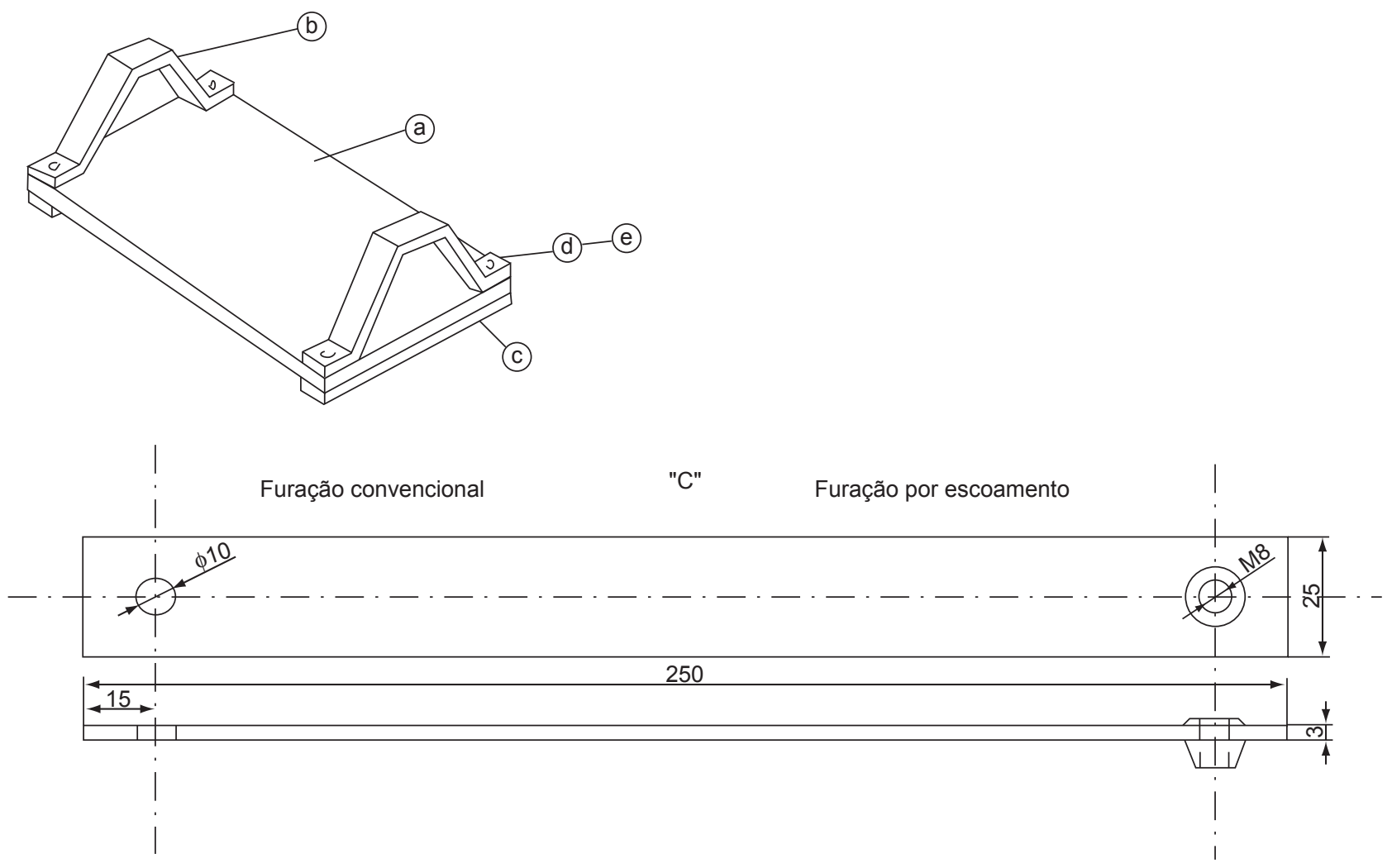

Figura 5. Conjunto para a validação do modelo.

Tabela 12. Equações dos custos da fase de Aquisição e Estocagem.
Equação
$\mathbf{K A E}=\mathbf{K}_{M P}+\mathbf{K}$ $\mathbf{K}_{\text {EspacoEMBPorcas }}+\mathbf{K F}_{\text {EMBPorcas }}$
$\mathrm{KAE}=$ custo de aquisição e estocagem por sistema de fixação (UM)

\section{Componentes}

\begin{tabular}{cc}
$\begin{array}{c}\text { Processo } \\
\text { furação por } \\
\text { escoamento }\end{array}$ & $\begin{array}{c}\text { Processo } \\
\text { furação } \\
\text { convencional }\end{array}$ \\
\hline $\mathrm{f}$ & $\mathrm{f}$ \\
(chapa) & (chapa e porca)
\end{tabular}

$\mathrm{K}_{M P}=\mathrm{C}_{\text {Chapa }}+\mathrm{C}_{\text {Porca }} \cdot \mathrm{Q}_{\text {Porcas }}$

$\mathrm{K}_{M P}=$ custo de matéria-prima por sistema de fixação (UM)

0

$\mathrm{f}$

$\mathrm{K}_{\text {EspaçoEMBPorcas }}=\mathrm{Q}_{\text {EMBPorcas }} \cdot \mathrm{A}_{\text {EMBPorcas }} \cdot 668,71 / \mathrm{Q}_{S F}$

$\mathrm{K}_{\text {EspaçoEMBPorcas }}=$ custo do espaço utilizado pelas embalagens para porcas por sistema de fixação (UM)

(porca)

$\mathrm{Q}_{\text {EMBPorcas }}=$ quantidade de embalagens necessárias para armazenar o volume diário de porcas no

estoque principal

$\mathrm{A}_{\text {EMBPorcas }}=$ área ocupada pela embalagem $\left(\mathrm{m}^{2}\right)$

$\mathrm{Q}_{S F}=$ quantidade de sistemas de fixação por ano

$\mathrm{Q}_{\text {EMBPorcas }}=\mathrm{V}_{\text {Porcas }} / \mathrm{V}_{\text {EMBPorcas }}$

$\mathrm{V}_{\text {Porcas }}=$ volume das porcas necessárias a cada dia $\left(\mathrm{mm}^{3}\right)$

$\mathrm{V}_{\text {EMBPorcas }}=$ capacidade volumétrica da embalagem $\left(\mathrm{mm}^{3}\right)$

$\mathrm{KF}_{\text {EMBPorcas }}=\mathrm{Q}_{\text {EMBPorcas }} \cdot \mathrm{C}_{\text {EMBPorcas }} \cdot 0,35 / \mathrm{Q}_{S F}$

$\mathrm{KF}_{\text {EMBPorcas }}=$ custo de embalagem por sistema de fixação (UM)

0

$\mathrm{C}_{\text {EMBPorcas }}=$ custo de aquisição da embalagem (UM) 
Tabela 13. Equações dos custos da fase de Manufatura.

\begin{tabular}{|c|c|c|}
\hline \multicolumn{3}{|c|}{$\begin{aligned} \mathbf{K M A}= & \mathbf{K F}_{E Q U I P}+\mathbf{K V}_{E Q U I P}+\mathbf{K}_{M O D}+\mathbf{K}_{F E R R}+\mathbf{K}_{E s p a c o E M B S \text { catata }}+\mathbf{K F}_{E M B S \text { Latat }}+\mathbf{K A U X} \\
& \mathbf{K M A}=\text { custo de manufatura por sistema de fixação }(\mathbf{U M})\end{aligned}$} \\
\hline Componentes & $\begin{array}{l}\text { Processo furação } \\
\text { por escoamento }\end{array}$ & $\begin{array}{l}\text { Processo furação } \\
\text { convencional }\end{array}$ \\
\hline $\begin{array}{l}\mathrm{KF}_{E Q U I P}=\left[\mathrm{A} .668,71+\mathrm{C}_{E Q U I P} \cdot 0,26\right] / \mathrm{Q}_{S F} \\
\mathrm{KF}_{E Q U I P}=\text { custo fixo do equipamento para cada sistema de fixação (UM) } \\
\mathrm{C}_{\text {EQUIP }}=\text { custo de aquisição do equipamento (UM) }\end{array}$ & $\begin{array}{l}\text { f (furadeira para } \\
\text { escoamento e } \\
\text { rosqueadeira) }\end{array}$ & $\begin{array}{l}\mathrm{f} \text { (furadeira } \\
\text { convencional e } \\
\text { furadeira para } \\
\text { escareamento) }\end{array}$ \\
\hline $\begin{array}{l}\mathrm{KV}_{E Q U I P}=\mathrm{t}_{o p} \cdot\left(\mathrm{C}_{E Q U I P} / 88000+\mathrm{N}_{E Q} \cdot 0,524\right) / 3600 \\
\mathrm{KV}_{E Q U I P}=\text { custos variáveis do equipamento por sistema de fixação }(\mathrm{UM}) \\
\mathrm{t}_{o p}=\text { tempo de operação dos equipamentos utilizados na manufatura para cada sistema de } \\
\text { fixação (s) } \\
\mathrm{N}_{E Q}=\text { potência do equipamento }(\mathrm{kW})\end{array}$ & $\begin{array}{l}\mathrm{f} \text { (furadeira para } \\
\text { escoamento e } \\
\text { rosqueadeira) }\end{array}$ & $\begin{array}{l}\mathrm{f} \text { (furadeira } \\
\text { convencional e } \\
\text { furadeira para } \\
\text { escareamento) }\end{array}$ \\
\hline $\begin{array}{l}\mathrm{K}_{\mathrm{MOD}}=\mathrm{t}_{t m} \cdot \mathrm{S}_{O P E} / 3600 \\
\mathrm{~K}_{M O D}=\text { custo de mão-de-obra de manufatura por conjunto de sistema de fixação (UM) } \\
\mathrm{t}_{t m}=\text { tempo total para a manufatura de cada chapa componente do sistema de fixação (s) } \\
\mathrm{S}_{O P E}=\text { salário dos operadores de furadeiras e rosqueaderias }(\mathrm{UM} / \mathrm{h})\end{array}$ & $\begin{array}{l}\text { f (furadeira para } \\
\text { escoamento }+ \\
\text { rosqueadeira) }\end{array}$ & $\begin{array}{l}\mathrm{f} \text { (furadeira } \\
\text { convencional e } \\
\text { furadeira para } \\
\text { escareamento) }\end{array}$ \\
\hline $\begin{array}{l}\mathrm{K}_{F L}=\mathrm{C}_{F L} \cdot \mathrm{Q}_{\text {porcas }} / 20000 \\
\mathrm{~K}_{F L}=\text { custo da ferramenta Flowdrill }{ }^{\circledast} \text { por sistema de fixação (UM) } \\
\mathrm{K}_{M C}=\mathrm{C}_{M C} \cdot \mathrm{Q}_{\text {porcas }} \cdot \text { e } / 50000 \\
\mathrm{~K}_{M C}=\text { custo da ferramenta macho para conformação por sistema de fixação (UM) } \\
\mathrm{e}=\text { espessura da chapa (mm) } \\
\mathrm{K}_{B R O}=\mathrm{C}_{B R O} \cdot \mathrm{Q}_{\text {porcas }} \cdot \text { e } / 5000 \\
\mathrm{~K}_{B R O}=\text { custo da broca helicoidal por sistema de fixação (UM) } \\
\mathrm{K}_{E S C}=\mathrm{C}_{E S C} \cdot \mathrm{Q}_{\text {porcas }} \cdot \mathrm{d} / 300000 \\
\mathrm{~K}_{E S C}=\text { custo da broca escareadora por sistema de fixação (UM) } \\
\mathrm{d}=\text { diâmetro do furo (mm) }\end{array}$ & $\begin{array}{l}\text { f (vida do flowdrill } \\
\text { e do macho de } \\
\text { conformação) }\end{array}$ & $\begin{array}{l}\mathrm{f} \text { (vida da broca e do } \\
\quad \text { escareador) }\end{array}$ \\
\hline $\begin{array}{l}\mathrm{K}_{\text {EspaçoEMBSucata }}=\mathrm{Q}_{E M B S \text { Sucata }} \cdot \mathrm{A}_{E M B \text { Sucata }} \cdot 668,71 / \mathrm{Q}_{S F} \\
\mathrm{~K}_{\text {EspaçoEMBSucata }}=\text { custo do espaço utilizado pelas embalagens utilizadas para a sucata por } \\
\text { sistema de fixaça (UM) } \\
\mathrm{Q}_{\text {EMBSucata }}=\text { quantidade de embalagens necessárias para armazenar o volume diário da } \\
\text { sucata gerada na furação convencional } \\
\mathrm{A}_{\text {EMBSucata }}=\text { área ocupada pela embalagem utilizada para a sucata }(\mathrm{m} 2) \\
\mathrm{Q}_{\text {EMBSucata }}=\mathrm{V}_{\text {Sucata }} / \mathrm{V}_{\text {EMBSucata }} \\
\mathrm{V}_{\text {Sucata }}=\text { volume da sucata produzida na furação convencional a cada dia }\left(\mathrm{mm}^{3}\right) \\
\mathrm{V}_{\text {EMBSucata }}=\text { capacidade volumétrica da embalagem }\left(\mathrm{mm}^{3}\right)\end{array}$ & 0 & $\begin{array}{l}\mathrm{f}(\text { cavacos da } \\
\text { furação) }\end{array}$ \\
\hline $\begin{array}{l}\mathrm{KF}_{\text {EMBSucata }}=\mathrm{Q}_{\text {EMBSucata }} \cdot \mathrm{C}_{E M B \text { Sucata }} \cdot 0,35 / \mathrm{Q}_{S F} \\
\mathrm{KF}_{\text {EMBSucata }}=\text { custo de embalagem para sucata por sistema de fixação (UM) } \\
\mathrm{C}_{\text {EMBSucata }}=\text { custo de aquisição da embalagem necessária para a sucata (UM) }\end{array}$ & 0 & $\begin{array}{l}\mathrm{f}(\text { cavacos da } \\
\text { furação) }\end{array}$ \\
\hline $\begin{array}{l}\mathrm{K}_{A U X F L}=\mathrm{C}_{P A S T A} \cdot \mathrm{Q}_{\text {porcas }} / 20000 \\
\mathrm{~K}_{A U X F L}=\text { custo de pasta lubrificante por conjunto de sistema de fixação (UM) } \\
\mathrm{C}_{\text {PASTA }}=\text { custo da pasta lubrificante }(\mathrm{UM} / \mathrm{kgf}) \\
\mathrm{K}_{A U X M C}=\mathrm{C}_{O L E O} \cdot \mathrm{Q}_{\text {porcas }} / 100000 \\
\mathrm{~K}_{A U X M C}=\text { custo do óleo para rosqueamento por conjunto de sistema de fixação (UM) } \\
\mathrm{C}_{O L E O}=\text { custo do óleo }(\mathrm{UM} / \mathrm{l}) \\
\mathrm{K}_{A U X B R O}=\mathrm{C}_{F L U C O R} \cdot \mathrm{Q}_{\text {porcas }} \cdot \mathrm{d}^{2} \cdot \mathrm{e} / 44675,07 \\
\mathrm{~K}_{A U X B R O}=\text { custo de fluido de corte por conjunto de sistema de fixação (UM) } \\
\mathrm{C}_{F L U C O R}=\text { custo do fluido de corte }(\mathrm{UM} / \mathrm{l})\end{array}$ & $\begin{array}{l}\text { f (pasta e óleo de } \\
\text { corte) }\end{array}$ & f (fluido de corte) \\
\hline
\end{tabular}


Tabela 14. Equações dos custos da fase de Montagem.

Equação
$\mathbf{K M}=\mathbf{K}_{M O M}+\mathbf{K} \mathbf{F}_{F M O N}+\mathbf{K}_{\text {EspaçoEMBPorcas }}+\mathbf{K F}_{\text {EMBPorcas }}$ $\mathrm{KM}=$ custo de montagem por sistema de fixação (UM)

Componentes

\section{Processo furação Processo furação por escoamento convencional}

f (pré-fixação do f (pré-fixação do parafuso) parafuso, porcas e chave adicional)

$\mathrm{K}_{\text {MOM }}=\mathrm{t}_{m} \cdot \mathrm{S}_{\text {MON }} / 3600$

$\mathrm{K}_{M O M}=$ custo de mão-de-obra de montagem por conjunto de sistema de fixação (UM)

$\mathrm{t}_{m}=$ tempo adicional necessário para a montagem de cada conjunto de sistema

de fixação (s), calculado conforme Apêndice E, Tabela 24

$\mathrm{S}_{M O N}=$ salário dos montadores $(\mathrm{UM} / \mathrm{h})$

$\mathrm{KF}_{F M O N}=\mathrm{C}_{F M O N} \cdot 0,35 / \mathrm{Q}_{S F}$

$\mathrm{KF}_{F M O N}=$ custo fixo das ferramentas adicionais utilizadas na montagem de porcas

$\mathrm{f}$ (chave adicional por sistema de fixação (UM)

$\mathrm{C}_{F M O N}=$ custo de aquisição das ferramentas adicionais utilizadas na montagem de porcas por sistema de fixação (UM)

\begin{tabular}{|c|c|c|}
\hline $\mathrm{K}_{\text {EspaçoEMBPorcas }}=\mathrm{Q}_{\text {EMBPorcas }} \cdot \mathrm{A}_{\text {EMBPorcas }} \cdot 668,71 / \mathrm{Q}_{S F}$ & 0 & $\mathrm{f}$ (porcas) \\
\hline $\mathrm{KF}_{\text {EMBPorcas }}=\mathrm{Q}_{\text {EMBPorcas }} \cdot \mathrm{C}_{\text {EMBPorcas }} \cdot 0,35 / \mathrm{Q}_{S F}$ & 0 & $\mathrm{f}$ (porcas) \\
\hline
\end{tabular}

Tabela 15. Equações dos custos da fase de Manutenção.

\begin{tabular}{|c|c|c|}
\hline \multicolumn{3}{|c|}{$\begin{array}{c}\qquad M M C=\mathbf{K}_{M O C}+\mathbf{K F}_{F C L} \\
\text { KMC = custo de manutenção anual pelo cliente por sistema de fixação (UM/ano) }\end{array}$} \\
\hline Componentes & $\begin{array}{c}\text { Processo furação } \\
\text { por escoamento }\end{array}$ & $\begin{array}{c}\text { Processo furação } \\
\text { convencional }\end{array}$ \\
\hline $\begin{array}{l}\mathrm{K}_{M O C}=\mathrm{t}_{m c} \cdot \mathrm{S}_{M O C} \cdot \mathrm{Q}_{M C L} / 3600 \\
\mathrm{~K}_{M O C}=\text { custo de mão-de-obra do cliente por conjunto de sistema de fixação por ano (UM/ano) } \\
\mathrm{t}_{m c}=\text { tempo necessário para a manutenção de cada conjunto de sistema de } \\
\text { fixação (s), calculado conforme Apêndice E, Eq. } 77 \\
\mathrm{~S}_{M O C}=\text { salário dos funcionários do cliente que realizam a manutenção (UM/h) } \\
\mathrm{Q}_{M C L}=\text { quantidade de manutenções realizadas pelo cliente em um ano }\end{array}$ & $\begin{array}{c}\mathrm{f} \text { (chave } \\
\text { combinada e } \\
\text { pré-fixação do } \\
\text { parafuso) }\end{array}$ & $\begin{array}{l}\text { f (porcas, chaves } \\
\text { combinadas e } \\
\text { pré-fixação do } \\
\text { parafuso) }\end{array}$ \\
\hline $\begin{array}{l}\mathrm{KF}_{F C L}=\mathrm{C}_{F C L} \cdot 0,35 \\
\mathrm{KF}_{F C L}=\text { custo fixo das ferramentas utilizadas na manutenção por sistema } \\
\text { de fixação por ano (UM/ano) } \\
\mathrm{C}_{F C L}=\text { custo de aquisição das ferramentas utilizadas na manutenção (UM) }\end{array}$ & $\begin{array}{l}\text { f ( chave } \\
\text { combinada) }\end{array}$ & $\begin{array}{l}\mathrm{f}(2 \text { chaves } \\
\text { combinadas })\end{array}$ \\
\hline
\end{tabular}

\section{Considerações finais}

A literatura e a observação de várias situações industriais demonstram que o ciclo de vida dos produtos está diminuindo constantemente e as decisões do projetista são cada vez mais importantes para assegurar a performance e o resultado final das empresas. A determinação de custos nas fases de projeto está se tornando cada vez mais importante para a sobrevivência das organizações, sob o ponto de vista de sua redução e também sob a ótica de agilidade quanto às rápidas mudanças de mercado.

O modelo descrito neste trabalho propõe uma abordagem inovadora para a estimativa de custos nas fases iniciais de desenvolvimento de produtos, pois produz informações que subsidiam o processo de tomada de decisão na escolha de sistemas de fixação desmontáveis.
Este modelo ressalta, também, a preocupação com o cliente final (que é quem mantém a empresa fabricante - é o cliente quem paga o produto), pois os custos de Manutenção durante a vida do produto são quase sempre omitidos pelo projetista na definição do projeto, o que pode prejudicar a imagem do produto junto aos clientes.

A base de dados do modelo está fundamentada na bibliografia e informações de fornecedores citados nas referências deste artigo.

Uma vez finalizada esta etapa desta investigação, observa-se a oportunidade de ampliação de seu escopo, envolvendo uma análise mais apurada do ciclo de vida dos produtos. Também, percebe-se o potencial deste modelo para contemplar questões ambientais (descarte do produto), utilização de diferentes materiais e ferramentas, bem como outros processos (de fabricação e mesmo de fixação) até aqui não considerados. 


\section{Sumário das equações aplicáveis ao modelo Pro-Comp}

Com o objetivo de melhor visualização das diversas equações de custos desenvolvidas e utilizadas no modelo, a seguir são apresentadas as Tabelas 12, 13, 14 e 15, contendo cada fase considerada no modelo. Equações com os cálculos de tempos de cada fase também foram tratadas e desenvolvidas para atender e suportar este modelo.

\title{
An approach model to a comparative economic assessment of alternatives for threaded fastening systems
}

\begin{abstract}
The demands for quality and delivery time have been growing in the majority of manufacturing sectors. However, these demands are strongly dependent on previous stages decisions, mostly those related to the product development process. Several of these decisions are influenced by the experience or personal preferences from the design team. Additionally, most products depend on the assembly processes, which can assume different configurations (e.g. permanent (riveting) or non-permanent (fastening) joining solutions). From the environment point of view, the reversible systems perform a fundamental role during the product development process. The choice for a fastening system occurs during the design stage. Thus, this paper aims at the development of a model that supports the decision making process when choosing reversible fastening systems, based on the economic aspects of the manufacturing/assembling process examined. The entry data and model structure are well adhered to the industrial reality, theoretical parameters, and data from the experiments. The model considers the costs factors originated from: i/ purchasing and storage; ii/ manufacturing; iii/ assembling; and iv/maintenance; which are the main stages of a component life cycle. The set of equations that support the model is also presented. A preliminary model test illustrates its capabilities for capturing the cost differences amongst fastening systems for a specific assembly, from parameters defined at early stages of the design process.
\end{abstract}

Keywords: Model for cost assessment. Economic analysis. Fastening systems. Comparative cost analysis.

\section{Referências bibliográficas}

ANDREASEN, M. M. et al. Design for Assembly. 2 ed. United Kingdom: IFS Publications, 1988. 212 p.

BARNES, R. M. Estudo de movimentos e de tempos: Projeto e medida de trabalho. 6 ed. São Paulo: Editora Edgard Blücher Ltda., 1995. 635 p.

BOOTHROYD, G.; DEWHURST, P.; KNIGHT, W. Product Design for Manufacture and Assembly. New York: Marcel Dekker Inc., 1994. 540 p.

BRAllA, J. G. et al. Handbook of Product Design for Manufacturing. Singapore: McGraw-Hill Book Co., 1988. $1049 \mathrm{p}$.

CASAROtTo Filho, N.; KOPITTKE, B. H. Análise de Investimentos. 9 ed. São Paulo: Editora Atlas S.A., 2000. $458 \mathrm{p}$.

DAETZ, D. The Effect of Product Design on Product Quality and Product Cost. Quality Progress, June, p. 63-67, 1987.

DELOITTE TOUCHE TOHMATSU. Pesquisa de salários e benefícios: Cargos técnicos, administrativos e operacionais. Novembro 2002.

DRABUS. Disponível em: <http://www.drabus.com>. Acesso em: 27 Junho 2001.

FERRARESI, D. Usinagem dos metais: Fundamentos da usinagem dos metais. São Paulo: Editora Edgard Blücher Ltda., 1970. $754 \mathrm{p}$.
FLOWDRILL $^{\circledR}$. Guia Técnico. 3 ed. Flowdrill BV,Utrecht, Holanda, Set. 1995. 32 p.

FLOWDRILL $^{\circledR}$. User guide. Flowdrill BV, Utrecht, Holanda, 2000. 32 p.

FLOWDRILL. Homepage do Fabricante. Disponível em: <http:// www.flowdrill.nl>. Acesso: 27 Junho 2001.

HICKS, T. G. et al. Standard Handbook of Engineering Calculations. 2 ed. New York: McGraw-Hill Inc., 1985.

HUNDAL, M. S. Time and Cost Driven Design. In: ASME NATIONAL DESIGN ENGINEERING CONFERENCE, March 13-15, 1995, Chicago. Proceedings... New York: ASME, 1995. Design for Manufacturability.

MICHAELS, J. V.; WOOD, W. P. Design to cost. New York: John Wiley \& Sons Inc.,1989. 413 p.

OSG Ferramentas de Precisão Ltda. Informações de Produtos: Ferramentas de Precisão. São Paulo, [2001?].

PAHL, G.; BEITZ, W. Engineering Design: A Systematic Approach. London: Springer, 1996.

PIEKARSKI, J. C. B. Modelo para Análise Econômica Comparativa entre Alternativas de Sistemas de Fixação. Curitiba, 2004. 181 p. Dissertação (Mestrado) - PPGEM, UTFPR.

PUGH, S. Total Design: Integrated Methods for Successful Product Design. London: Addison-Wesley, 1990. 
RECEITA FEDERAL. Secretaria da Fazenda. Disponível em: <http:// www.receita.fazenda.gov.br>. Acesso em: 15 de Setembro de 2003.

ROZENFELD, H. et al. Gestão de Desenvolvimento de Produtos: Uma Referência para Melhoria do Processo. São Paulo: Saraiva, 2006.

SKF Ferramentas S.A. Manual Técnico. São Paulo, 1987. 261 p.

STARK, J. W. B. Connections in cold-formed sections. Sheet Metal Industries, February, p. 108-119, 1977.

TOLEDO Jr., I. F. B. Cronoanálise: Base da racionalização, da produtividade, da redução de custos. São Paulo: Itys-Fides Bueno de Toledo Jr. \& Cia. Ltda., 1986. 205 p.
Ullman, D. G. The Mechanical Design Process. New York: McGraw-Hill, 1997.

UNIMEX NV. Disponível em: <http://www.formdrill.com>. Acesso em: 27 Junho 2001.

VALE, C. E. Implantação de Indústrias. Rio de Janeiro: Livros Técnicos e Científicos Editora S.A., 1975. 354 p.

VIANNA, C. S. V. Manual prático das relações trabalhistas. 4 ed. São Paulo: Editora LTR Ltda., 2000. 904 p.

\section{Sobre os autores}

\section{João Carlos Barreto Piekarski}

PPGEM - Volvo do Brasil Ltda.

Alameda das Acácias, 110, Curitiba - PR

e-mail: joaopiekarski@yahoo.com.br

\section{Carlos Cziulik}

PPGEM - UTFPR - Universidade Tecnológica Federal do Paraná

Av. Sete de Setembro, 3165, Curitiba - PR

e-mail: cziulik@utfpr.edu.br

Agradecimentos: Os autores agradecem o apoio recebido do Programa de Pós-graduação em Engenharia Mecânica e de Materiais (PPGEM) e do Departamento Acadêmico de Mecânica, ambos da Universidade Tecnológica Federal do Paraná 